\title{
A Configuração das Redes Sociais de Suporte a Pessoas com Câncer: um Olhar sob o Prisma da Informação e Comunicação em Saúde
}

\author{
Configuration of Social Networks to Support People with Cancer: a View from the Perspective of Information and \\ Communication in Health \\ La Configuración de las Redes Sociales de Suporte a Personas con Cáncer: una Mirada Bajo el Prisma de la \\ Información y de la Comunicación en Salud
}

Fabiana Felix Ribeiro'; Regina Maria Marteleto²

Resumo

Introduçáo: $\mathrm{O}$ câncer de cabeça e pescoço engloba vários tipos de tumores. Entre eles, destacam-se o câncer de laringe e o de cavidade oral. O câncer de laringe ocupa a primeira posição e representa o segundo tipo de câncer respiratório mais comum do mundo. No Brasil, é o oitavo tipo de câncer mais incidente entre homens. Já o câncer de cavidade oral ocupa a décima quinta posição entre todos os tipos de cânceres e, no Brasil, representa o quinto mais comum. Ambos os tipos atingem principalmente homens com idade superior a 40 anos. Objetivo: Identificar como se constroem as formas de comunicação, fluxos de informação e a apropriação de conhecimentos pelos pacientes matriculados na clínica de cabeça e pescoço do Instituto Nacional de Câncer José Alencar Gomes da Silva e suas redes sociais, na perspectiva de que tais recursos são fundamentais para lidar com as mudanças e necessidades impostas pela situação de adoecimento. Método: Trata-se de um estudo de natureza qualitativa, pautado na metodologia de história oral de vida, utilizando como apoio teórico os conceitos de narrativa e redes sociais. Foram realizadas três entrevistas com pacientes em estágios diferentes de tratamento. Conclusáo: O processo de informação e comunicação que se configura nas redes sociais dos pacientes é fundamental na construção de estratégias de suporte e proteção social ao longo do tratamento. Esse conhecimento torna-se fundamental na interlocução com as políticas públicas, tendo em vista a possibilidade de participação e ampliação de direitos.

Palavras-chave: Comunicação em Saúde; Neoplasias; Redes Sociais.

\begin{abstract}
Introduction: Head and neck cancer encompasses several types of tumors. Notable types include cancer of the larynx and cancer of the oral cavity. Laryngeal cancer is the most common of such cancers and is the second most common type of respiratory cancer worldwide. In Brazil, it is the eighth leading type of cancer among men. Mouth cancer ranks 15 th among all cancers and is the fifth most common cancer in Brazil. Both types of cancer mainly affect men over the age of 40 . Objective: To identify how forms of communication, information flows, and knowledge appropriation are constructed by cancer patients under treatment at the Head and Neck Clinic of the José Alencar Gomes da Silva National Cancer Institute and registered with its social networks, from the perspective that such resources are fundamental to deal with the changes and necessities imposed by their illness. Method: This was a qualitative study, based on the methodology of collecting oral life histories, using narrative concepts and social networks as theoretical support. Patients were interviewed at three different stages of treatment. Conclusion: The process of information and communication that patients configure on their social networks is fundamental for the construction of support strategies and social protection throughout the course of treatment. Such knowledge becomes fundamental in the interaction with public policies, in view of the possibility of participation and the broadening of rights.

Key words: Health Communication; Neoplasms; Social Networking.
\end{abstract}

Resumen

Introducción: El cáncer de cabeza y cuello engloba varios tipos de tumores. Entre ellos, se destacan el cáncer de laringe y el de cavidad oral. El cáncer de laringe ocupa la primera posición y representa el segundo tipo de cáncer respiratorio más común del mundo. En Brasil, es el octavo tipo de cáncer más incidente entre hombres. El cáncer de cavidad oral ocupa la décima quinta posición entre todos los tipos de cáncer y, en Brasil, representa el quinto más común. Ambos tipos alcanzan principalmente a hombres de más de 40 ańos. Objetivo: Identificar como se construyen las formas de comunicación, flujos de información y apropiación de conocimiento por los pacientes matriculados en la clínica de cabeza y cuello del Instituto Nacional de Cáncer José Alencar Gomes da Silva y sus redes sociales, en la perspectiva de que tales recursos son fundamentales para tratar con los cambios y necesidades impuestos por la situación de enfermedad. Método: Se trata de un estudio de naturaleza cualitativa, pautado en la metodología de historia oral de vida, utilizando como apoyo teórico los conceptos de narrativa y redes sociales. Fueron realizadas tres entrevistas con pacientes en fases diferentes del tratamiento. Conclusión: El proceso de información y comunicación que se configura en las redes sociales de los pacientes es fundamental en la construcción de las estrategias de suporte y protección social a lo largo del tratamiento. Ese conocimiento se hace fundamental en la interlocución con las políticas públicas, teniendo en cuenta la posibilidad de participación y ampliación de derechos.

Palabras clave: Comunicación en Salud; Neoplasias; Redes Sociales.

${ }^{1}$ Assistente Social do Instituto Nacional de Câncer José Alencar Gomes da Silva (INCA). Rio de Janeiro (R)), Brasil. E-mail: fabiana.ribeiro@inca.gov.br.

${ }^{2}$ Pesquisadora-Titular do Instituto Brasileiro de Informação em Ciência e Tecnologia/Ministério da Ciência, Tecnologia, Inovações e Comunicações (Ibict/MCTIC). Rio de Janeiro (RJ), Brasil. E-mail: regina.mar@ibict.br.

Endereço para correspondência: Fabiana Felix Ribeiro. Rua João Alfredo, 38 - apto. 501 - Tijuca. Rio de Janeiro (RJ), Brasil. CEP 20511-390. 


\section{INTRODUÇÃO}

O câncer é um problema de saúde pública, principalmente nos países periféricos e, nas próximas décadas, espera-se que o seu impacto sobre a população corresponda a $80 \%$ dos mais de 20 milhôes de casos novos estimados para $2025^{1}$. O câncer de cabeça e pescoço engloba vários tipos de tumores. Entre eles, destacam-se o câncer de laringe e o de cavidade oral. O câncer de laringe ocupa a primeira posição e representa o segundo tipo de câncer respiratório mais comum do mundo. No Brasil, é o oitavo tipo de câncer mais incidente entre homens. Já o câncer de cavidade oral ocupa a décima quinta posição entre todos os tipos de cânceres e, no Brasil, representa o quinto mais comum. Ambos os tipos atingem principalmente homens com idade superior a $40 \mathrm{anos}^{2}$.

O termo câncer é utilizado genericamente para representar um conjunto de mais de 100 neoplasias, incluindo tumores malignos de diferentes localizaçóes. A cirurgia, a radioterapia (especialidade médica que utiliza como forma de tratamento a radiação ionizante) e a quimioterapia (método que utiliza compostos químicos, no tratamento de doenças causadas por agentes biológicos ou pelo adoecimento por diferentes tipos de cânceres) são os principais tratamentos de combate e de controle do câncer ${ }^{3}$.

De acordo com Alvarenga et al. ${ }^{3}$, o câncer de cabeça e pescoço é um termo coletivo para denominar e descrever os tumores malignos de trato aerodigestivo superior. Essa regiāo inclui a cavidade oral, a faringe e a laringe. Um subgrupo maior dos carcinomas de cabeça e pescoço é referido como "câncer oral", surgindo nas mucosas da boca (lábios, base da língua, língua, assoalho bucal e palato duro) e faringe (orofaringe, hipofaringe e nasofaringe). Cerca de $40 \%$ dos cânceres de cabeça e pescoço ocorrem na cavidade oral, $15 \%$ na faringe e $25 \%$ na laringe e o restante em regiôes das glândulas salivares e tireoide.

Entre os tipos de câncer, aproximadamente $80 \%$ a $90 \%$ estáo associados a causas externas, como, por exemplo, o tabagismo. O câncer de cabeça e pescoço atinge principalmente homens em idade laborativa e está associado à ingestão de bebidas alcoólicas e ao tabagismo. O uso dessas substâncias pode provocar o câncer de boca, orofaringe, laringe $e^{4}$.

Verifica-se, como consequência do tratamento, a alteração da imagem corporal ${ }^{5}$, especificamente, a alteração da imagem facial e da regiáo do pescoço, como algo recorrente e que contribui para gerar ainda mais impactos na vida desses sujeitos, em razão das limitaçôes que poderão surgir posteriormente ao tratamento para a reinserção nas suas redes de relaçóes sociais e no mundo do trabalho ${ }^{6}$.
Os desafios postos para o enfrentamento da doença são muitos, principalmente no que se refere aos países periféricos que têm baixo gasto público em saúde, onde doenças crônicas e doenças infectocontagiosas coexistem, em uma conjuntura na qual ainda se busca avançar no acesso ao diagnóstico precoce e no tratamento nas fases iniciais da doença ${ }^{6}$, situaçáo já controlada ou resolvida em países centrais.

Quanto a esse aspecto, verifica-se, na estimativa do Instituto Nacional de Câncer José Alencar Gomes da Silva (INCA), para o ano de $2012^{4}$, a preocupação em abordar a dimensão social do câncer, considerando o seu impacto devastador na organização familiar, visto que, muitas vezes, a pessoa adoecida é o chefe da família e seu provedor ou no caso de outros membros que precisam interromper, muitas vezes, projetos de vida, como o estudo e o trabalho, para exercerem açóes de cuidado no interior da família.

Esse tipo de adoecimento se constitui em uma experiência complexa que engloba as dimensóes objetivas e subjetivas da vida. Como dimensão objetiva, apresenta como característica a longa duração, tratamentos invasivos e que vão requerer cuidados paliativos, visto que são incuráveis. As dimensões subjetivas traduzem-se nas dificuldades em relaçáo aos aspectos psicológicos para o enfrentamento da doença, dificuldades de ordem socioeconômica para gerenciamento das condiçóes materiais para a realizaçáo do tratamento e em relação a fragilidades dos vínculos sociais e de apoio fundamentais para a promoção do cuidado necessário 7 . $\mathrm{O}$ processo de tratamento/cuidado vai requerer o suporte e o apoio de pessoas ou grupos que compóem as relaçôes sociais dos pacientes e, por isso, definidas neste artigo como suas redes sociais, no sentido de relaçóes que podem ser construídas ao longo da vida ou que possam se configurar diante desse contexto ${ }^{8}$.

O conceito de redes sociais é polissêmico e transversal a várias áreas do conhecimento, não existindo uma teoria de redes sociais ${ }^{9}$. Conforme esclarece Acioli ${ }^{10}$, o conceito nasce na Antropologia Social tendo em vista a análise etnográfica das redes de estruturas de parentesco. Outras áreas do conhecimento podem focar os estudos de redes sociais do âmbito das relaçôes sociais e suas conexóes com pessoas e instituiçóes em uma perspectiva de relação com a estrutura social, enquanto, para alguns autores, principalmente a partir das décadas de 1980 e 1990, o uso tecnológico das redes, sobretudo, relacionado ao avanço das tecnologias da informação, ganha destaque nas formas eletrônicas de conexóes como um meio de acesso a informaçóes. Em todas essas diferentes abordagens, verifica-se que há uma relação direta com a informação, entendendo informaçáo como processo de trocas que ocorrem de forma permanente. 
Nesta pesquisa, busca-se conhecer as redes sociais dos pacientes no que tange às suas relaçóes sociais e conexões que são construídas e reconstruídas ao longo da vida e, principalmente, como essas redes se organizam para fornecer apoio e suporte diante da situação de adoecimento. No que toca a dimensão desta pesquisa, foram desconsiderados os usos e abordagens do conceito de redes sociais referente ao espaço das interaçóes e conexôes em meio tecnológico/virtual.

Considera-se que, na perspectiva do adoecimento, as redes podem se movimentar em torno da necessidade de proteção e cuidado de pessoas adoecidas crônicas, mobilizar recursos e respostas possíveis a situaçóes extremas, questão que exige organização e reorganização constante desses grupos e de suas relaçôes?

Conceitualmente, as redes de proteção e cuidado ao paciente podem ser denominadas redes sociais e/ou redes de apoio social. A rede social segundo Griep ${ }^{11}$ pode ser considerada como a estrutura social por meio da qual o apoio é fornecido. Essa rede é composta por pessoas com as quais o paciente tem algum vínculo, sendo geralmente pessoas da família ou que pertencem a uma rede de relaçôes formal. Já as redes de apoio social ${ }^{12}$ podem ser consideradas como o auxílio recebido por pessoas ou grupos, sem vínculos formais com o paciente, mas que podem gerar trocas sociais importantes com efeitos positivos para ambos. Ou seja, existem açóes e recursos em movimento nas redes sociais que se destacam na constituiçâo de conhecimento e que adquirem valor nas relaçôes sociais.

Com base nesse movimento, a network analysis ${ }^{13}$, como teoria de análise de redes sociais, permite olhar para três definiçóes analíticas constitutivas das redes sociais: os recursos que produzem e fazem circular, a estrutura social na qual estão inseridas e as açôes que se propagam nas redes. Nesse aspecto, a morfologia das redes pode proporcionar acesso a conhecimentos que condicionam as práticas sociais e políticas dos sujeitos ${ }^{11}$.

Com relação às redes sociais, Marteleto ${ }^{9}$ sinaliza que os estudos sobre redes representam um grande avanço em termos de compreensão dos fenômenos sociais, pois permitem sair do foco sobre o individual para se pensar a dimensão das relaçóes sociais. Ainda segundo a autora ${ }^{9}$, é importante destacar que as redes sociais se movimentam a partir das construçôes em torno da informação e da comunicação; ou seja, nas possibilidades de aprendizado, de trocas de conhecimento e na ação coletiva dos indivíduos em rede, podendo oferecer algumas pistas para se pensar a configuração dos elos sociais, a organização da social e a cultura, bem como suas expressóes no processo de trabalho em saúde?.

No espaço do hospital ${ }^{14}$, torna-se inevitável que os profissionais de saúde e instituiçôes participem do cotidiano de vida e de cuidados a essas pessoas, visto que o hospital se torna um laboratório vivo de experiências em torno do significado que as redes movimentam, apropriando-se de forma mais interativa das informaçóes, produzindo e compartilhando conhecimento para o gerenciamento do cuidado. Essa questáo reforça a ideia de que a análise de redes sociais é por excelência um campo interdisciplinar que perpassa várias áreas do conhecimento ${ }^{13}$.

Como exemplo do trabalho com redes, faz-se referência ao que ocorre no espaço da clínica de cabeça e pescoço do INCA, principalmente no que se refere à intervenção do profissional Assistente Social junto à equipe de saúde e pacientes/familiares. No que diz respeito à interação junto à equipe de saúde, o profissional atua na busca contínua voltada para conferir visibilidade às condiçôes de vida e de trabalho da populaçáo atendida, bem como de sua dinâmica na estrutura social e no âmbito das suas redes de relaçôes sociais, procurando promover a interação com essas redes no sentido da mobilização dos recursos existentes, tendo em vista minimizar vulnerabilidades, garantindo o acesso, a participação e o direito à saúde.

O trabalho com redes sempre fez parte do escopo de intervenção do Assistente Social, embora seja pouco discutido no seio da categoria. Na perspectiva atual, ganha novo vulto, visto que, diante das mudanças sociais, se torna evidente o enfraquecimento das formas comunitárias de vida e o aumento da mobilidade social, ao mesmo tempo em que cresce o desafio para a construção de respostas institucionais frente à complexidade das demandas apresentadas ${ }^{15}$. Tais questóes levantam a importância de compreensão dessas dinâmicas em uma perspectiva da construçâo de conhecimento sobre as redes sociais e suas formas de interação com a estrutura social em transformação ${ }^{16}$.

Desse modo, busca-se conhecer o movimento das redes sociais de apoio dos pacientes na interação com outras redes, principalmente com a rede institucional e com a rede de políticas públicas, considerando suas limitaçóes e potencialidades na busca de soluçôes para situaçóes complexas que se apresentam como desafios cotidianos.

O espaço da clínica de cabeça e pescoço se constitui em campo fértil de pesquisa, visto que, nele, ganham visibilidade a realidade social e relacional dos pacientes e de suas redes de apoio, bem como as repercussóes dessa realidade no processo de tratamento.

Em pesquisas realizadas sobre a produçáo científica em torno do tema redes sociais na saúde, não foram identificados estudos prévios que abordem a aproximação entre o processo de tratamento e a realidade social dos pacientes com câncer, na interface com suas redes sociais.

$\mathrm{O}$ conhecimento empírico permite perceber que os fatores de risco associados a esse tipo de câncer estão 
relacionados ao escasso acesso a açóes de promoção e prevençáo de saúde, condiçóes precárias de trabalho e renda, pouca escolaridade, aos vínculos sociais frágeis construídos ao longo da vida, entre outros determinantes sociais. Portanto torna-se fundamental compreender essa realidade, por meio da pesquisa científica, de modo a identificar como se configuram as redes sociais e suas interaçôes possíveis, no processo de tratamento oncológico.

A partir dessas consideraçôes, o objetivo deste trabalho foi identificar como se configuram as redes sociais de suporte e apoio aos pacientes com câncer de cabeça e pescoço, na tentativa de compreender os fluxos de comunicação e informação, bem como as bases em que se constroem a apropriação e a elaboração de conhecimentos, entendendo que tais recursos são significativos para lidar com as mudanças e necessidades colocadas pela situação do adoecimento.

\section{MÉTODO}

O espaço para realizaçáo da pesquisa foi a clínica de cabeça e pescoço que está localizada no Hospital de Câncer I (HCI), maior unidade hospitalar do INCA. A referida clínica se destaca por ser uma das maiores clínicas cirúrgicas do INCA.

A metodologia utilizada na pesquisa foi a entrevista, baseada na história oral de vida, englobando aspectos da história de vida das pessoas entrevistadas e situando dentro delas a temática do adoecimento por câncer e a configuração de suas redes sociais nessa experiência.

A história oral é uma técnica que se expressa como uma forma de saber na medida em que traz à tona experiências humanas tanto individuais quanto coletivas. Nesse aspecto, há uma preocupação não só com o registro, mas também o intuito em divulgar e tornar públicos conhecimentos e histórias como experiências que podem ser compartilhadas ${ }^{17}$.

A história oral de vida admite entrevistas livres, decorrentes de narrativas, que englobam aspectos prováveis e improváveis da vida, todas as precisôes e imprecisóes contidas na experiência das pessoas e que, por isso, têm um traço significativo para a pesquisa ${ }^{17}$.

Sobre o conceito de narrativa, Canesqui ${ }^{7}$ refere que a experiência da enfermidade crônica tende a ser biograficamente informada por intermédio das narrativas das pessoas adoecidas, e vão configurando alguns pontos importantes como: as percepçóes e estratégias para enfrentamento, a questão da autoimagem alterada, a ideia de ruptura biográfica ${ }^{18}$, a questão do estigma e da identidade coletiva. Nesse processo, a experiência de adoecimento abriga, ao mesmo tempo, aspectos de ordem individual e coletiva que se entrelaçam em uma rede de percepçóes e significados. O diálogo entre essas duas dimensóes e o conhecimento elaborado nesse processo podem ser expressos pelas narrativas ${ }^{7}$.

Desse modo, os conceitos de narrativa e de redes sociais foram fundamentais como referenciais teóricos na pesquisa. Esses conceitos balizam o sentido da experiência como um conhecimento que é tecido em movimento em busca de uma nova interação com a vida a partir das mudanças e desafios que possam surgir, como os colocados pela situação de enfermidade.

O trabalho de campo se concentrou na realizaçáo de três entrevistas, com duas mulheres e um homem, matriculados na clínica de cabeça e pescoço e em estágios diferentes de tratamento; duas mulheres com idades de 42 e 70 anos e um homem com 49 anos; uma mulher residente na cidade do Rio de Janeiro e os demais em outros municípios do Estado do Rio de Janeiro. A escolha teve como critério a identificação de pacientes em fluxo de atendimento pelo Serviço Social na clínica, sem preocupaçáo com recorte de gênero, sendo um paciente ainda sem definição de tratamento, outro já com a definição de tratamento (aguardando cirurgia) e o terceiro em fase de controle. Essa escolha justifica-se pela necessidade de aprofundamento das entrevistas em diferentes fases do tratamento, com o objetivo de conhecer as principais questóes existentes em cada uma, sobretudo acerca da articulação das redes sociais e as suas possíveis transformaçôes ao longo do processo de tratamento. As entrevistas ficaram extensas em função da quantidade de informação e reflexóes, visto se tratar de processos que exigem elaboração pelos entrevistados acerca de diferentes fases de suas vidas, buscando situar as experiências de vida em relação à experiência de adoecimento. Além disso, o tempo restrito para a conclusão da pesquisa também influenciou para a manutenção dessa escolha. As entrevistas foram realizadas em sala fechada individualmente com cada paciente e gravadas e transcritas posteriormente. Foi realizada uma entrevista com cada paciente, cujo tempo de duração foi em média de 40 minutos.

O roteiro de entrevista foi elaborado a partir da construção das seguintes categorias estruturadas a começar dos objetivos do estudo e consideradas centrais para a compreensão da configuração das redes sociais dos usuários: antecedentes (marcos pessoais e familiares), adoecimento e tratamento (percepçóes e descoberta da doença, trajetória e compreensão do tratamento proposto), elos pessoais existentes e adquiridos (redes de apoio já existentes ou que se constituíram durante o tratamento), elos institucionais (acolhimento e troca de conhecimento com o universo institucional) e participação e direito à saúde (percepção sobre a configuração de interesses 
comuns e do direito à saúde a partir do contexto do tratamento).

A pesquisa foi submetida aos Comitês de Ética em Pesquisa do INCA (CAEE 05748212.5.3001.5274) e do IOC-Fiocruz (CAEE 05748212.1.0000.5248) e aprovada em janeiro de 2013. Todos os participantes foram convidados a participar da entrevista e previamente orientados sobre os objetivos e metodologia da pesquisa. Antes do seu início, preencheram duas vias do Termo de Consentimento Livre e Esclarecido (TCLE) conforme os princípios éticos e legais exigidos pela resolução número 196/96, do Conselho Nacional de Saúde.

\section{RESULTADOS E DISCUSSÃO}

\section{ANTECEDENTES}

Os entrevistados fizeram referência a questôes que consideraram centrais na estrutura de suas relaçóes familiares remetendo-se a fases marcantes da vida, aspectos da convivência familiar e o significado de família.

Percebeu-se, em suas narrativas, que, ainda na fase da infância, em função do contexto de vida marcado por situaçóes de pobreza e alcoolismo, vivenciaram o distanciamento da rede familiar (pais e irmãos) tendo sido criados por outros familiares ou outras famílias conhecidas, com melhores condições financeiras. Esse aspecto surge como uma prática comum entre famílias que não tinham condiçóes de criar muitos filhos e, por isso, buscavam auxílio em outras famílias, parentes e pessoas conhecidas, até que as condiçóes de vida melhorassem e os filhos pudessem entáo retornar para o seio de sua família de origem. Suas narrativas surgiram repletas de sofrimento em relação a distância dos pais e irmãos. Referiram que se sentiam como pessoas que não tiveram infância, pois na realidade tinham que trabalhar para essas famílias, com as quais não tinham vínculo afetivo, como forma de compensar tal acolhimento.

Mesmo diante desse afastamento, seus esforços foram canalizados para a possibilidade de uma futura reaproximação com a sua família de origem. No caso específico de nossos entrevistados, observou-se que não houve efetivamente um rompimento de vínculos, visto que, mesmo diante do afastamento da rede familiar, os vínculos foram mantidos (uns de modo mais frágil e outros menos), e eles destacaram o compromisso derivado da consanguinidade e da obrigação da família em gerar proteção, aspecto reforçado em suas narrativas.

Esse discurso reforça o sentido de família como unidade biológica e sua força nesse sentido, ao mesmo tempo em que reitera o seu significado como fenômeno social e cultural; ou seja, para além de ser um fenômeno biológico, a família é condicionada pelas diferenças e desigualdades sociais que interferem nas suas relaçóes sociais. A ideia de família tem passado por transformaçóes substanciais, mas verifica-se que a ideia de família para a população empobrecida ganha contornos de uma rede que se estende a vários lares, com o objetivo de garantia de sobrevivência e organização do mundo das pessoas ${ }^{19}$.

Nas entrevistas, percebeu-se a construção do significado de família como eixo principal de suporte que é reforçado pelos entrevistados no sentido de que a família é a instituição por meio da qual o apoio é fornecido. Mesmo que os vínculos estejam fragilizados, essa rede é caracterizada como formal e legitimada pela estrutura social para gerar o cuidado ${ }^{20}$.

\section{AdOECIMENTO E TRATAMENTO}

A fase de identificação do adoecimento e definição diagnóstica se constitui em um momento marcado por muitas dúvidas e ansiedade. A chegada ao serviço de saúde para tratamento é muitas vezes tardia e pode repercutir em uma não possibilidade de cura. Ao mesmo tempo, a preocupação com a doença vem associada à dificuldade em administrar os cuidados e atençáo exigidos pelo tratamento. Sobre a demora em iniciar o tratamento, o entrevistado A afirma que:

[...] A doença começou com uma afta na boca e tomava remédio... ia ao Hospital do Andaraí e me davam remédio [...] Os médicos [fora do INCA] falavam que não era nada de mais... eu não ligava, por que eu acreditava neles... e foi crescendo... eu acreditava nos médicos... eu era analfabeta e eles eram os médicos... e deu no que deu... a dor aumentou e eu corri... enquanto eu tomava comprimido e passava, tudo bem... não sabia que chegar a esse ponto... A situaçáo foi se agravando e passou da língua para a parte de cima [maxilar] e isso foi a gota d'água...foi feita a biópsia e encaminhamento pro INCA.

Nesse caso, as narrativas se apresentam também como um espaço possível de registro para denunciar tais situaçōes vivenciadas pelos pacientes em sua trajetória em busca de tratamento.

Em relação ao tratamento, os pacientes também referem o medo da cirurgia em funçáo da possibilidade de alteração da imagem facial. O entrevistado A cita que:

quando soube que tinha que 'cortar' o pescoço e o médico disse que tinha 99\% de chance de colocar o aparelho (traqueostomia) para a respiraçáo... aí comecei a chorar.

Já o entrevistado C: 
Dei graças a Deus que vou fazer radioterapia e não vou 'cortar' logo...tomara Deus que a quimioterapia e a radioterapia resolvam e que náo precise cortar o rosto. Acho que é isso...

O significado do câncer, contido nas narrativas, traz os aspectos individuais e coletivos que envolvem o medo da doença, a possibilidade de alteração da imagem do corpo $^{5}$ em função de intervenções cirúrgicas e a ruptura de projetos de vida ${ }^{18}$, antes em andamento, e que precisam ser interrompidos em função do adoecimento que inevitavelmente envolve as pessoas mais próximas e suas redes de apoio.

Outro aspecto relevante apresentado nas narrativas foi a forma como os entrevistados atribuem significado ao câncer em suas vidas. $\mathrm{O}$ surgimento do câncer apareceu como mais um fato, diante de tantos outros difíceis de serem gerenciados, tais como o desemprego, a violência, entre outros; mas possível de ser superado como tantos outros fatos da vida o foram. Nesse processo, buscaram-se formas de adaptação, equilíbrio e normalidade na interação com outras dimensôes e exigências da vida, como estratégia para se garantir a sustentação necessária ao enfrentamento da situação ${ }^{21}$.

A relação com o trabalho como forma de superação das dificuldades e organização da vida apareceu na narrativa de dois entrevistados.

A narrativa, a seguir, ilustra essa questão:

A vida é feita de muito trabalho e muita dificuldade[...] ter que cuidar de crianças pequenas, sair para trabalhar, foi uma vida muito difícil! Não tinha ninguém para olhar as crianças...ninguém pra ajudar! Quanto à doença [...]não me deixei abater por isso, não tô nem aí pra ela [...] vivendo numa comunidade, a gente tem a vida em risco todos os dias, a doença é só mais um risco! Agora ficar em cima de uma cama [...] trabalhar no trailer sem poder abrir uma garrafa! Aí eu morro!

Nessa narrativa, o trabalho ocupa um lugar importante como forma de se manter longe o estresse, em atividade constante, com a mente em equilíbrio. Estar ativo é melhor do que estar doente ou se entregar ao estresse do risco diário.

A possibilidade de apoio fornecido pelas redes sociais e instituiçóes de acordo com Valla ${ }^{22(328)}$ pode "funcionar como uma espécie de amortecedor contra os efeitos nocivos de eventos estressantes e inesperados da vida, como hospitalização, separação de cônjuges ou demissão do emprego." Assim, diante de tantas adversidades da vida, as classes populares (re)significam a doença como mais um evento a ser administrado, diante de tantos outros.

\section{ELOS PESSOAIS EXISTENTES E ADQUIRIDOS}

$\mathrm{O}$ entrevistado A aponta que, mesmo tendo sido possível retomar o contato com a família, não conseguiu uma reaproximação de fato que pudesse gerar suporte afetivo nesse momento de sua vida. Nesse caso, encontrou em outras redes o suporte para o enfrentamento das questôes do dia a dia, incluindo a situação de adoecimento. Trata-se das redes sociais não ancoradas na família e que compreendem os vizinhos, amigos, igreja, e outros grupos que possam gerar apoio social como forma de proteção à saúde e garantia de sobrevivência pelas classes populares, que conseguem manter a sua existência por meio desse apoio ${ }^{22}$. Assim, essas redes de apoio ou suporte se fundamentam com base nas trocas sociais e significam um apoio importante, mas se colocam, em grande maioria, em uma postura da não obrigação de garantir proteção social exclusivamente, podendo assumir um papel central no suporte diante de uma situação de adoecimento. Esse tipo de apoio pode se configurar diante da coparticipaçáo de pessoas e outras redes, propiciando novos contatos e trocas de conhecimento, incluindo o próprio acolhimento da unidade de saúde e de suas equipes. Esse fluxo de informação e comunicação que se constrói movimenta atores diferenciados envolvidos direta ou indiretamente com o suporte, fomentando a combinação de recursos materiais ou simbólicos que visam a garantir a sobrevivência. Nas narrativas, essa questão surgiu desde a circulação de ajuda material de amigos do trabalho para as despesas iniciais em relação ao tratamento, o reconhecimento coletivo do próprio valor nos grupos sociais a partir da experiência do câncer, bem como na situação em que pessoas, de origens sociais diferentes, interagem sensibilizadas com a condição de adoecimento do outro.

Pessoas fora da comunidade comparecem no meu trailer, gente da prefeitura, deputados que me abraçam e dizem 'força, minha velha!' são pessoas que querem saber de mim, me ajudam e que frequentam a minha vida.

Isso movimenta novos significados sobre a experiência do adoecimento que pode contribuir no fortalecimento e organização desses grupos.

$\mathrm{O}$ que foi identificado nesse processo é que tanto a família quanto as redes não ancoradas na família apresentam a possibilidade de promover o cuidado na perspectiva do não abandono e da cooperação entre os envolvidos. Já os entrevistados $\mathrm{B}$ e $\mathrm{C}$ reafirmam a função de centralidade da família como grupo principal de suporte e cuidado diante de situaçóes difíceis, entre elas o momento de adoecimento. 
Ainda sobre as redes não ancoradas na família, a inserção e a circulação nesses grupos vão depender também da postura assumida por seus membros, por meio de mecanismos de valoraçáo construídos diante do outro e das possibilidades de troca que tenham valor para todos os envolvidos. No caso de situações de adoecimento, os exemplos de perseverança e superação destacados no grupo podem se converter em sentimentos de reconhecimento e pertencimento, legitimando também o próprio grupo. Esses aspectos estáo fortemente presentes na narrativa do entrevistado A:

Depois que eu me separei... pelo testemunho que eu dei (na igreja)... as pessoas diante de um problema, às vezes, se descabelam, fazem coisas que não deveriam fazer por desespero, mas eu corri para a igreja... e isso foi uma surpresa para as pessoas... achavam que era só imediato e que depois que passasse me afastaria da igreja. Estou na igreja há 5 anos... E hoje todos me respeitam e me saúdam com a paz de Deus!

Nessa narrativa, a religiosidade e a fé surgem como uma das formas de sustentação, como recurso importante de ser mobilizado e revelam as relaçóes entre as redes humanas e as redes invisíveis (espirituais) no sentido da busca pela ampliação da proteçấo, do sentido de estabilidade e do fortalecimento da identidade para o enfrentamento do adoecimento. Nesse sentido, a reflexão de Valla ${ }^{22(325)}$ esclarece que:

Para as classes populares[...] as práticas religiosas têm-se mostrado um caminho central em busca de um estado mental diferente, capaz de permitir o vislumbre de saídas e para a construção de espaços coletivos de troca de saberes e emoçôes capazes de apontar pistas de superação do encurralamento pelo raciocínio que a consideraçáo de tantos fatos negativos trazem [...] Isso tem desencadeado formas solidárias e criativas de enfrentamento da difícil situação em que se encontram.

\section{ELOS INSTITUCIONAIS}

$\mathrm{O}$ acolhimento aos pacientes que ingressam na rede institucional para tratamento é uma ferramenta importante e que tem contribuiçáo efetiva no seu processo de inserção no espaço do hospital, facilitando a sua ambientação, a apreensão do processo em uma perspectiva de produção de autonomia e participação. $\mathrm{O}$ acolhimento propicia a sociabilidade e as trocas de informação fomentando a construção do conhecimento em torno da experiência.

Para o entrevistado C, o ingresso na rede institucional é compreendido como momento inicial de apropriação de novas informaçóes sobre as possibilidades de tratamento e de cura, que se confronta com as dúvidas e preocupaçóes em torno das condições concretas para sua realização:

Mas a gente não sabia disso (que existem recursos que podem facilitar o acesso e a continuidade do tratamento - direitos sociais da pessoa com câncer previstos em legislação) e aí gastamos muito dinheiro até chegar aqui! Aqui me falaram que eu posso fazer um cartão de passagem! Verdade? (Passe Livre).

O processo comunicativo e o acesso a essas informaçôes que vão se configurando ao longo de tratamento contribuem em muitos casos para a reafirmação da cidadania, visto que, ao longo do processo, se consolidam conhecimentos sobre a experiência na interação com os demais atores, fator que mobiliza as pessoas para a participaçáo coletiva e a luta por direitos. Em algumas situaçóes, aqueles que estiveram excluídos de seus direitos básicos de cidadania ao longo da vida, devido a contextos de pobreza e isolamento social, acabam encontrando, na situação adoecimento, a possibilidade desse exercício de participaçáo, ao se depararem com a experiência do sofrimento vivenciada de forma individual, mas também coletiva, podendo inclusive ressignificarem o sentido da sua ação no mundo, em que as trocas de informaçáo compartilhadas e a identificação com o outro podem gerar a potência para açóes criativas e enfrentamento do status quo.

Nesse aspecto, o acolhimento na rede institucional é pontuado, pelos entrevistados, como fator importante e decisivo para ampliar o acesso aos direitos e informaçóes fundamentais que possam viabilizar a continuidade do tratamento ${ }^{21}$.

No entanto, verifica-se que as organizações de saúde estão, muitas vezes, estruturadas com base em uma hierarquia técnica que tende a não reconhecer a importância do acolhimento e da dimensão ética do cuidado como fundamentais para o desenvolvimento do trabalho em saúde. Desse modo, segundo Caillé23(58), "em toda organização, se vê que a eficácia geral depende da capacidade de dádiva e de 'entrega' dos seus membros. Nada pode funcionar se esses não se ajudarem permanentemente com conselhos técnicos, apoios afetivos e informações de todo tipo."

\section{PARTICIPAÇÃO E DIREITO À SAÚDE}

As narrativas evidenciam que a experiência do adoecimento se expressa individualmente como um conhecimento que pode ser compartilhado. Na narrativa do entrevistado $\mathrm{A}$, pode-se verificar a potência advinda do sentido construído em torno do compartilhamento de experiências: 
Todos trocam informaçôes sobre a doença... e falam... a gente vai sair dessa! Fiz amizades boas aqui (com familiares e pacientes). Falo por telefone e pergunto pelos pacientes delas... se está tudo bem... São pessoas que ficaram internadas e acompanhantes.

O entrevistado B afirma que "Isso serve de lição de vida e eu posso ajudar outras pessoas também”. Nesse caso, o conhecimento conquistado pela experiência é considerado um valor, um recurso que pode ser compartilhado com as pessoas e instituiçóes, promovendo a continuidade do movimento nas redes.

\section{CONCLUSÃO}

A pesquisa revela a centralidade da rede familiar como referência principal nas narrativas da formação dos entrevistados e o quanto eles remetem-se à vida familiar para explicar os modos de enfrentamento das dificuldades que surgem ao longo da vida. Por meio da família, capta-se a ordem simbólica do mundo que nos cerca, aprendendo as regras básicas de convivência a partir de seu discurso. Nesse aspecto, são elaboradas as suas próprias reflexôes, muitas vezes, em discordância com a postura familiar (considerando-se as respectivas realidades e dificuldades inerentes) ao mesmo tempo em que a adoção de suas próprias percepçôes sinalizam escolhas e conhecimentos próprios que são construídos nessa trajetória e que influenciam a construção de suas próprias redes a partir dessas referências. Considera-se que as redes sociais dos pacientes desempenham um papel fundamental na garantia de cuidados e de proteção social e apresentam um potencial articulador de informaçóes que podem ampliar-se na medida em que a rede institucional atua na perspectiva de um acolhimento. Esse cuidado deve englobar a disposição de compreender as singularidades desses sujeitos, suas histórias de vida, identificando os elos e vínculos sociais existentes e que podem ser religados ou construídos mediante a necessidade de cuidado e assistência

As informações geradas pela pesquisa podem fundamentar novos projetos de pesquisa e de intervençáo. Os fluxos de comunicação e informação que se configuram nas redes de apoio dos pacientes podem e devem ser melhor compreendidos pela rede institucional. Constata-se, ainda, a dificuldade dos profissionais de saúde, geralmente oriundos da classe média, de compreenderem a fala e o fazer das classes populares.

Essa reflexão é fundamental, pois, desse modo, os profissionais de saúde estarão contribuindo para que o conhecimento construído pelos pacientes e suas redes sociais abra possibilidades de interlocução no espaço do hospital e também fora dele, podendo ampliar, por exemplo, o diálogo com as políticas públicas tendo em vista construção de direitos afinados com as reais necessidades de saúde desses grupos.

Os dados desta pesquisa visam a contribuir para que as equipes de saúde possam, para além de seu conhecimento técnico, se lançar e transitar em zonas diferentes de conhecimento que favoreçam intervençóes criativas, considerando a diversidade presente na realidade social em nosso país e, ao mesmo tempo, os aspectos gerais e singulares envolvidos em cada situação particular. Essa circulação de conhecimentos é algo vital no processo de assistência em saúde. Faz fluir informação, comunicação, participação e cuidado.

\section{CONTRIBUIÇÕES}

Ambas as autoras contribuíram igualmente em todas as etapas do manuscrito.

\section{DECLARAÇÃO DE CONFLITO DE INTERESSES}

Nada a Declarar.

\section{REFERÊNCIAS}

1. Organização Mundial de Saúde. International Agency for Research on Cancer, 2014. [acesso em 2018 jun 24] Disponível em: http://www.who.int/cancer/ publications/WRC_2014/en/

2. Brasil. Ministério da Saúde. Instituto Nacional de Câncer José Alencar Gomes da Silva. Estimativa 2018: Incidência de câncer no Brasil. Rio de Janeiro: INCA; 2017.

3. Alvarenga LM, Ruiz MT, Pavarino-Bertelli ÉC, Ruback MJC, Maniglia JV et al. Avaliação epidemiológica de pacientes com câncer de cabeça e pescoço em um hospital universitário do noroeste do estado de São Paulo. Rev. Bras. Otorrinolaringol. [Internet] 2008 [acesso em out 3]; 74(1): 68-73. Disponível em http:// www.rborl.org.br/.

4. Instituto Nacional de Câncer José Alencar Gomes da Silva. Estimativa 2012: Incidência de Câncer no Brasil. Rio de Janeiro: INCA; 2011.

5. Pedrola FT, Zago MMF. A imagem Corporal Alterada do Laringectomizado: Resignação com a condição. RBC. 2000;46(4): 407-415.

6. Santos MCB, Silva LB, Estalino ES. Processo de trabalho do Serviço Social no campo da oncologia: Notas para reflexão. In: Senna MCM, Zucco LP, Lima ABR, organizadores. Serviço Social na Saúde Coletiva: Reflexóes e práticas. Rio de Janeiro: Garamond; 2012:251-272.

7. Canesqui AM, organizador. Olhares socioantropológicos sobre os adoecidos crônicos. São Paulo: Hucitec, 2007.

8. Silva LB. Condições de Vida e Adoecimento por Câncer. Libertas 2010; 10 (2):172-187. 
9. Marteleto RM. Redes sociais, mediação e apropriação de informação: situando campos, objetos e conceitos na pesquisa em ciência da informaçáo. Tendências da Pesquisa Brasileira em Ciência da Informação. 2010;3(1): 27-46.

10. Acioli S. Redes sociais e teoria social: Revendo os fundamentos do conceito. Revista Inf.Inf. 2007;12 (esp): 1-12.

11. Griep RH, Dora C, Faertein E, Lopes C. Confiabilidade teste-reteste de aspectos da rede social no estudo prósaúde. Rev. Saúde Pública. 2003;37(3): 379-385.

12. Valla VV. Educação popular, saúde comunitária e apoio social numa conjuntura de globalizaçáo. Cadernos de Saúde Pública1999; 15(2):7-14.

13. Fontes BASM. Redes sociais e saúde: Sobre a formação de redes de apoio social no cotidiano de portadores de transtorno mental. Rev. Bras. Ci. Soc. 2007; 26 (4): 87-104.

14. Wasserman W, Faust K. Social network analysis. Methods and applications. Cambridge: Cambridge University Press; 1999.

15. Mioto RCT. O trabalho com redes como procedimento de intervenção profissional: o desafio da requalificação dos serviços. 2002, Katálysis: 5(1):51-58.

16. Mercklè P. Sociologie des reseaux sociaux. Paris: La Découverte; 2004.

17. Meihy JCSB, Holanda F. História oral: como fazer como pensar. São Paulo: Contexto; 2011.

18. Bury M. Doença como ruptura biográfica. Rev. Tempos Actas de Saúde Coletiva. Artigo especial. [Internet] 2011 [acesso em 2017 jul 27]; 5(2): 41-55. Disponível em: http://www.tempusactas.unb.br/index.php/tempus/ article/.../963/905.

19. Gelinski CROG, Moser L. Mudanças nas famílias brasileiras e proteção desenhada nas políticas sociais. In: Mioto RCD, Campos MS, Carloto CM, organizadores. Familismo Direitos e Cidadania: Contradiçôes da Política Social. São Paulo, Cortez; 2015.

20. Sarti CA. A família como ordem simbólica. Psicologia USP. 2004; 15(3):11-28.

21. Canguilhem G. O Normal e o patológico. 5 ed. Rio de Janeiro: Forense universitária; 2002.

22. Valla VV. A vida religiosa como estratégia das classes populares na américa latina de superação da situação de impasse que marca suas vidas. In: Vasconcelos EM, organizador. A espiritualidade no trabalho em saúde. São Paulo: Hucitec, 2011: 310-340.

23. Caillé A. Dádiva, Care e Saúde. Sociologias. 2014; 16(36):42-59. 